\title{
The Simulation of One Metro Wheel Tread Temperature in Cycle Braking Condition
}

\author{
Hong-Ping ZHANGa ${ }^{a}$, Jian-Yong ZUO ${ }^{b}$ * , Guo HU ${ }^{b}$, Fei HAN ${ }^{b}$ and Tie-Feng \\ $\mathrm{ZHAO}$
}

\author{
aCRRC Qingdao Sifang Co., Ltd, TSINGDAO 266000, Shandong, China \\ b Institute of Railway \&Urban Mass Transit Research Tongji University. 200092,Shanghai, \\ China
}

zhanghongping@cqsf.com, *zuojy66@163.com

Keywords: Metro train, Pure air brake, Wheel temperature rise simulation, Temperature field.

\begin{abstract}
To simulate the tread temperature rise of the working subway train in the process of its normal operation and to explore the temperature rise limit of wheel tread during operation, finite element numerical simulation was used in this paper. Based on heat transfer theory and finite element method, a three-dimensional finite element model of the subway wheel was created. According to the braking condition of main line pure air brake, thermal simulation of wheel temperature field was conducted and finally the temp-rising law of the metro wheel was achieved. The results show that the wheel tread temperature first increased rapidly and then slowly decreased until the next brake in a period of "brake, stop, accelerate and coast", with the temperature raised about $110^{\circ} \mathrm{C}$ in a single brake. At first, the braking heat accumulated in the wheel, with the overall temperature gradually increasing. Then, after several consecutive braking processes, the overall temperature tended to be stable. The tread temperature reached its peak at $3766.5 \mathrm{~s}$, with the highest temp reaching $298.9^{\circ} \mathrm{C}$ during the 31 st braking process, not exceeding the limit of temperature rise $\left(400^{\circ} \mathrm{C}\right)$.
\end{abstract}

\section{Introduction}

At present, most of the domestic subway trains with the speed of lower than $80 \mathrm{~km} / \mathrm{h}$ are using the form of tread brake. In the center of the city, the construction of the station spacing is short, which leads to frequent starting and braking of the train, thus the reliability of the braking system is of great importance. Nowadays, the metro of the large and medium sized cities is moving towards the direction of heavy load and high speed, increasing the required braking force, the braking heat load, as well as the braking temperature. And once the brake wheel temperature rises above the temperature limit $\left(400^{\circ} \mathrm{C}\right)$, it will cause the wheel tread to generate hot cracks and expand along the tread circumference, which seriously affects the service life of the wheel and influences the braking safety. Therefore, for the actual operation of the train, it is of great reference importance to stimulate the wheel temperature rise during line operation and to explore the temperature rise limit for improving the brake shoe and the wheel life, ensuring traffic safety and braking safety.

\section{Wheel Model}

Taking a metro train as an example, the 3D geometry model of the wheel was built by using SolidWorks. To reduce the amount of computation, considering the wheel as the rotation body, the 1/6 model was adopted to carry out the grid division. As showed in fig.1, figure (a) was for the wheel geometry and figure (b) was for the wheel tetrahedral mesh model. CL60 steel was used as the wheel material. 


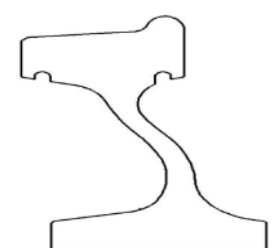

(a)cross-sectional geometry

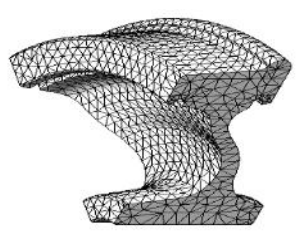

(b)Finite element mesh model

Figure 1 .Wheel geometry and computational model

\section{Simulation of Braking Parameters and Operating Conditions}

\section{Braking Parameters}

The main parameters were depicted as follows: train load form was AW3, load was $6.8 \mathrm{t}$ and the wheel diameter was $840 \mathrm{~mm}$. The braking acceleration was $1.0 \mathrm{~m} / \mathrm{s}^{\wedge} 2$, the maximum braking deceleration of pure air was $1 \mathrm{~m} / \mathrm{s}^{\wedge} 2$, and the braking mode was the tread brake.

\section{Introduction of Braking Condition}

The train running on the main line of a round-trip with the maximum operating speed of $80 \mathrm{~km} / \mathrm{h}$ used maximum pure air braking at each stop. Calculating the running time according to the actual distance between stations, each station spacing and ramp lines were shown in Table 1. The train stayed at the each station for about 30 seconds. The speed-time curve of the train in the course was shown in Figure 2 below.

Table 1 .Station spacing and ramp lines details

\begin{tabular}{|c|c|c|c|c|}
\hline No. & Center mileage & station spacing & slope & Ramp length \\
\hline Station 1 & YDK0+480 & \multirow{5}{*}{1511.8} & $+2 \%$ & 150 \\
\hline & & & $-14 \% 0$ & 200 \\
\hline & & & $-3.2 \%$ & 520 \\
\hline & & & $+5.39 \%$ & 300 \\
\hline & & & $+23.2 \% 0$ & 250 \\
\hline Station 2 & YDK1+991.8 & \multirow{5}{*}{1301.2} & $-2 \%$ & 170 \\
\hline & & & $-23 \% 0$ & 250 \\
\hline & & & $-6.4 \% 0$ & 320 \\
\hline & & & $+4.4 \%$ & 310 \\
\hline & & & $+25 \%$ & 260 \\
\hline Station 3 & YDK3+293 & \multirow{3}{*}{$\begin{array}{l}. \\
.\end{array}$} & $-2 \%$ & 160 \\
\hline & \multirow[t]{2}{*}{ 12010 } & & $-26.5 \%$ & 180 \\
\hline . & & & & \\
\hline Station 17 & YDK24+603177 & \multirow{6}{*}{1836.999} & $+2 \%$ & 230 \\
\hline & & & $+4 \%$ & 210 \\
\hline & & & $-27.45 \%$ & 260 \\
\hline & & & $+10.78 \%$ & 850 \\
\hline & & & $+20 \%$ & 360 \\
\hline Station 18 & YDK26+440.176 & & $+2 \%$ & 80 \\
\hline
\end{tabular}




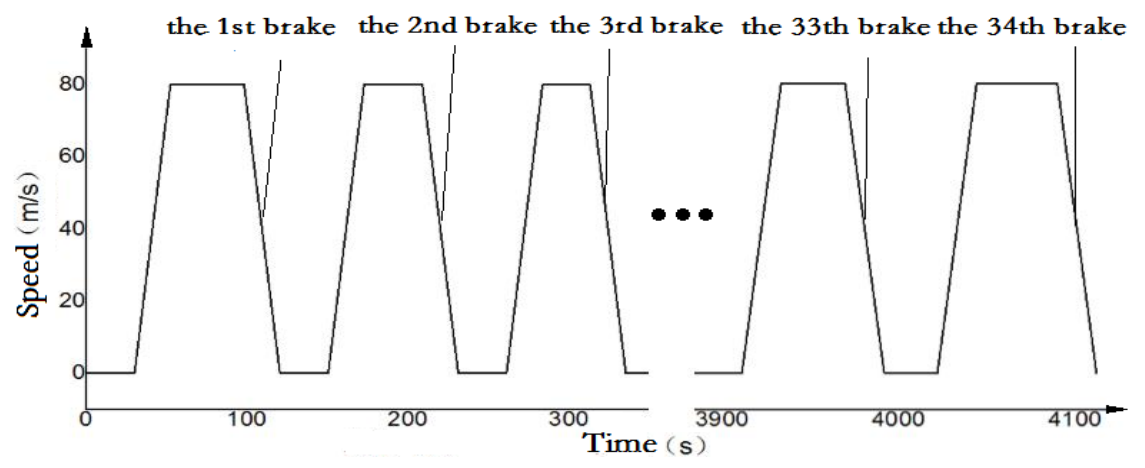

Figure 2. Train speed

\section{Boundary Condition Calculation}

In the braking process, most of the kinetic energy was transformed into heat friction between the wheel and the brake shoe. The wheel, as the research object, received the friction heat flux continuously from the wheel tread. At the same time, since the surface temperature of the wheel was higher than the ambient temperature and the wheel surface and ambient air were also in constant wheel heat convection, the wheels were constantly radiating energy in the form of heat radiation.

\section{Heat Flux Calculation}

The method of energy conversion was used to calculate the braking process of tread surface heat flux. During the braking process, the friction heat was generated by train kinetic energy. Assuming all of the train kinetic energy was turned into heat, then the friction energy Q (T) between the brake shoe and the wheel during the braking process could be calculated as (1):

$$
\begin{gathered}
Q(\mathrm{t})=\frac{1}{2} m v_{0}^{2}-\frac{1}{2} m v^{2}(\mathrm{t}) \\
v(\mathrm{t})=v_{0}-a t
\end{gathered}
$$

Where taking $\mathrm{m}$ as load $(\mathrm{kg}) ; v_{0}$ as the initial braking speed; $v(\mathrm{t})$ as the speed of the train during the braking process; $a$ as the emergency braking deceleration $\left(1.2 \mathrm{~m} / \mathrm{s}^{\wedge} 2\right)$.

During the actual braking process, due to the presence of wheel rail friction and air resistance and other factors, only a part of the kinetic energy generated during the braking process was conversed into heat, which was then absorbed by the wheel partly, with the other part of the heatis shoe absorption, taking into account the line ramp conditions, braking in ramp train gravity potential energy is converted into heat friction wheel brake shoe. Therefore, the heat flux Q (T) calculation formula is as follows(3):

$$
q(t)=\eta \frac{\frac{d Q(t)}{d t}+m g v(t) \sin a_{t}}{S}
$$

Where taking $\mathrm{S}$ as friction ring area of tread; $\eta$ as ratio coefficient about heat flux distributed to wheel tread (0.9); $\alpha_{t}$ as current ramp.

\section{Convection Heat Transfer Coefficient}

Heat exchange existed between the continuous running train and the outside world. This was realized by the simulation software controlling the convective heat transfer coefficient of the wheel surface. According to the theory of heat transfer, the coefficient of convective heat transfer on the surface of the wheel depends on the state of fluid flow, the physical properties of the fluid, the wall temperature and the geometry of the wall [5], i.e., 


$$
h_{c}=\frac{N u \cdot \lambda}{L}
$$

Where taking $N u$ as Nur number; $L$ as feature size of the solid surface; $\lambda$ as fluid thermal conductivity.

\section{Other Parameters}

All objects above absolute zero radiated energy outward continuously. And since energy radiated was very small during the running process, having little effect on the calculation results, the heat radiation condition of wheels was ignored.

The initial temperature and ambient temperature of the simulation model were set to $21.5^{\circ} \mathrm{C}$, the simulation time was $4112 \mathrm{~s}$, and the time substep was set to $1 \mathrm{~s}$.

\section{Simulation Results}

The simulation model was put into SolidWorks simulation for transient thermal analysis. By imposing the corresponding boundary conditions, meshing and simulation, we finally achieved the thermal results of the wheel during the cycle breaking process. Fig. 3 shows the temperature contour of the maximum temperature in the braking process.

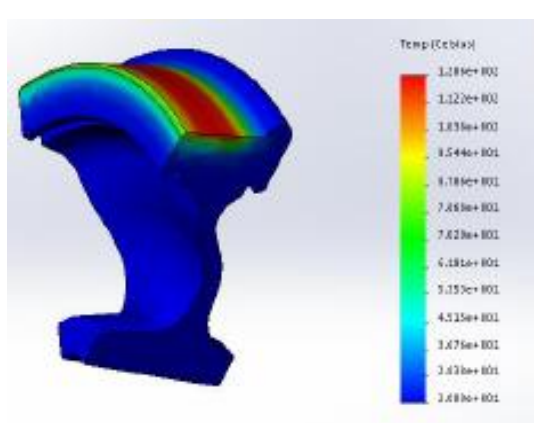

The $1^{\text {st }}$ brake

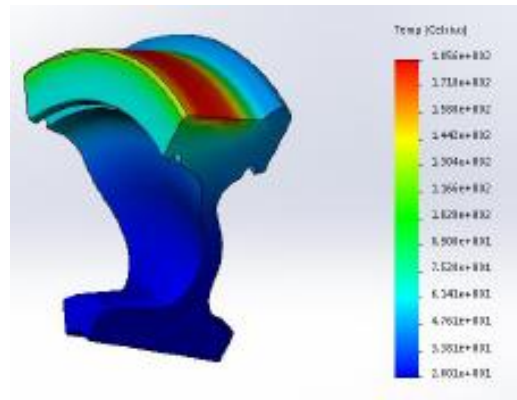

The $4^{\text {th }}$ brake

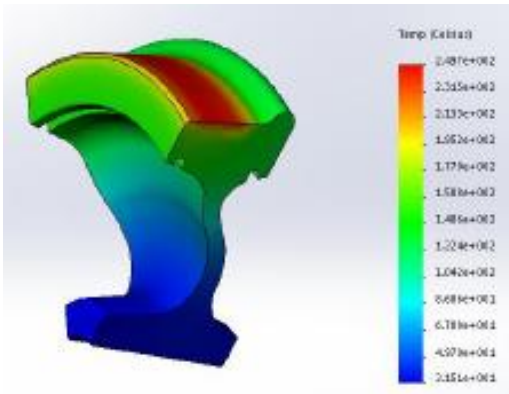

The $20^{\text {th }}$ brake

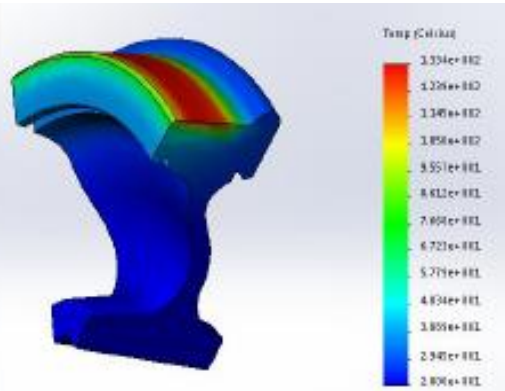

The $2^{\text {ed }}$ brake

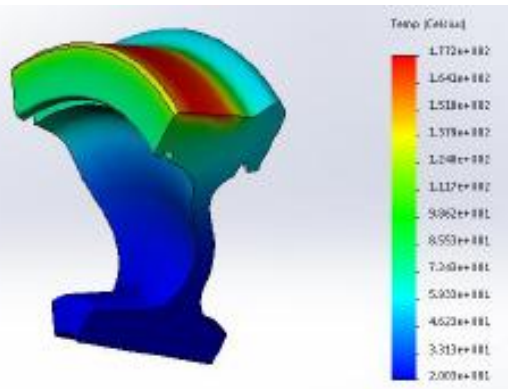

The $5^{\text {th }}$ brake

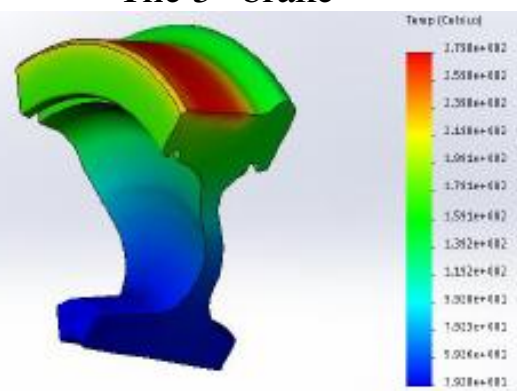

The $30^{\text {th }}$ brake

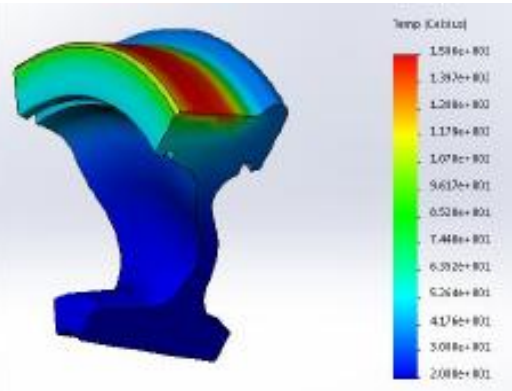

The $3^{\text {rd }}$ brake

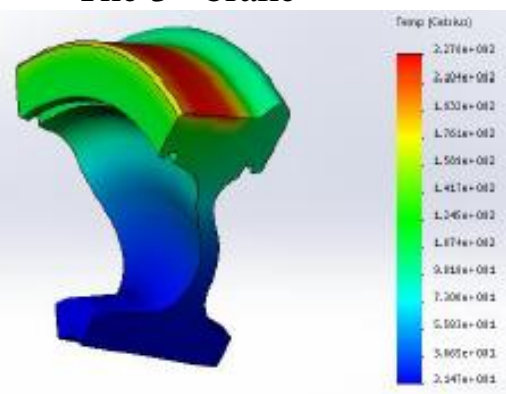

The $10^{\text {th }}$ brake

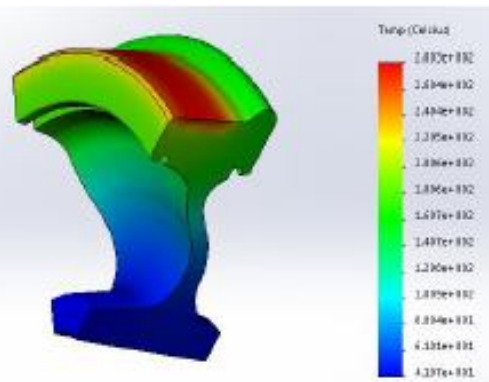

The $34^{\text {th }}$ brake

Figure 3 . The temperature contour of the maximum temperature in the each braking process

As showed in Figure 3, the temperature distribution showed the following rules: the highest temperature existed on the surface area in the process of brake wheel. Along the radial direction, the temperature turned from red to blue, indicating gradual decreased temperature. 
Under the cycle braking condition, due to the low initial temperature of the wheel, the temperature of the wheel outside the tread was low at first, showing deep blue. With the advance of the process, the green area experienced a gradual increase. After about twentieth braking, half of the wheel turned to green, and there was no obvious change latter. With the increase of braking cycles, the heat was accumulated in the interior wheel at first, and then gradually a balance was achieved, where the heat absorbed in the wheel tread in the braking process equivalent to that conducted to the air. In the first 5 cycles, the highest temperature of the tread was $120.6^{\circ} \mathrm{C}, 133.4^{\circ} \mathrm{C}, 150.4^{\circ} \mathrm{C}, 185.6^{\circ} \mathrm{C}, 177.2^{\circ} \mathrm{C}$. From the 30 th to 34 th cycles, the highest temperature was about $280^{\circ} \mathrm{C}$.To determine the rise limit of wheel tread temperature, we chose the highest temperature point $\mathrm{A}$ in the center area of the wheel tread, whose temperature curve during the cycle braking process was shown in figure 4.
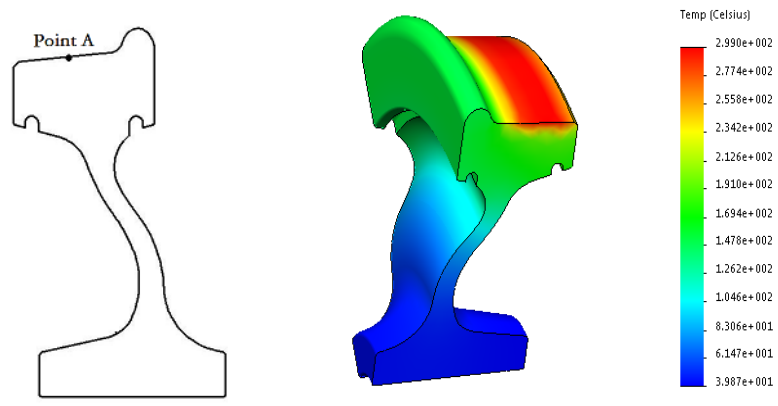

Figure 4 .Point A position and temperature graph

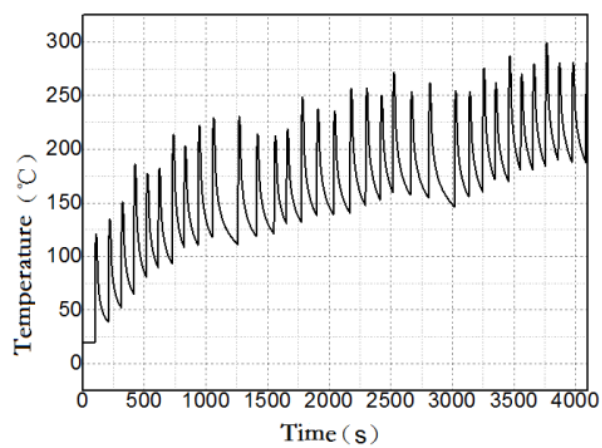

Figure 5. The maximum temperature in time wheel contours

It can be seen from Figure 4 that in a braking cycle, the wheel tread temperature firstly increased rapidly, then decreased gradually during the stop, acceleration and coast till the next brake. The rise of wheel tread temperature rose about $110^{\circ} \mathrm{C}$ during a single air brake. From the whole point of view, in the beginning of the continuous braking process, the friction heat accumulated in the wheel, resulting in a gradual increase in the overall temperature trend. After repeated braking, the heat absorption of the wheel tread and the convection heat dissipation of the surface reached a balance state, and the overall temperature was stable. In the simulation condition, the train experienced the cycle stop and the highest temperature of the tread appeared in the thirty-first stop process, 3766.5s, with the highest temperature reaching $298.9^{\circ} \mathrm{C}$. Fig. 5 illustrated the temperature distribution of the wheel at the moment.

\section{Conclusion}

Based on the pure air brake condition for a subway train line, this paper used the finite element analysis to stimulate the temperature field of the wheel and got the temperature rising law of the metro wheel under the condition.

1) In the braking process, the temperature of the wheel tread region was higher than that of the wheel. 
2) In a braking cycle, the wheel tread temperature increased at first then down to the next brake. The temperature rise of the wheel tread during a single brake was about $110^{\circ} \mathrm{C}$. From the view of the whole process, the friction heat in the previous several times were accumulated in the internal wheel and the overall temperature gradually increased. After continuous braking, heat absorbed and conducted reached an equilibrium state and the overall temperature tended to be stable.

3) The maximum temperature of the tread existed in the 31 st braking process, with the maximum temperature of $298.9^{\circ} \mathrm{C}$, no more than the temperature rise limit $\left(400^{\circ} \mathrm{C}\right)$.

\section{Acknowledgments}

This study was supported by the National Key Technology R\&D Program of the 12th Five Year Plan of China(2015BGA19B02), the Fundamental Research Funds for the Central Universities(2860219035), Natural Science Foundation of Shanghai (Grant No. 16ZR1438700)and Foundation of Traction Power State Key Laboratory of Southewest Jiaotong University (Grant No.TPL1706).

\section{References}

1. Qi ZHANF, Yu-guang WANG, Xiao-jiang ZHOU. Analysis on tread braking thermal load under different geometric parameters of subway train wheel structure[J]. Computer Aided Engneering, 2016, 25(2): 19-24. (in Chinese)

2. Zhi-kun SONG, Qing-fu HE. Research on Thermal Fatigue Damage in Wheel Braking [ J] .Rolling Stock , 1997 , 35( 9):43-46 . in Chinese)

3. Zhi-ding YING, Xiao-ning LI, Jian-pin LIN. The Temperature Cycle Test of Wheel Tread Braking for Freight Trains and the Simulation Analysis of the Temperature Field. 2010,31(3):71-75. (in Chinese)

4. Da-wei MA. Calculation and Application of Braking Heat Load on Railway Car. China Railway Science. 2000,21(4):35-37. (in Chinese)

5. Tian-sun ZHANG. Heat Transfer [M], 2nd ed. Beijing: China Electric Power Press, 2006.

6. Hai-yan ZHAO, ZHANG Hai-quan, TANG Xiao-hua, LIN Jian, CAI Zhi-peng, Thermal FEM analysis of passenger railway car brake discs [J]. J Tsinghua University (Sci-Tech), 2005,45(5):589-592.

7. Yong WANG. Jian-yong ZUO. Lei-lei GU. urban rail vehicle wheel heat intensity finite element temperature field [J]. Research of Urban Rail Vehicle. 2013, 13(2):42-47.(in Chinese) 